\title{
Assessment of Sustainability Development in Urban Areas of Morocco
}

\author{
Lahouari Bounoua ${ }^{1, *}$, Najlaa Fathi ${ }^{2}$, Meryem El Berkaoui ${ }^{3}$, Laila El Ghazouani ${ }^{4}$ and \\ Mohammed Messouli ${ }^{2}$ \\ 1 Biospheric Sciences Laboratory, NASA GSFC, Greenbelt, MD 20771, USA \\ 2 Department of Environmental Sciences, Faculty of Sciences Semlalia, Cadi Ayyad University, \\ Marrakesh 40000, Morocco; f.najlaae@gmail.com (N.F.); messouli@gmail.com (M.M.) \\ 3 Laboratory of Plant Physiology and Biotechnology, Faculty of Sciences, Mohammed V University, \\ Rabat 10001, Morocco; elberkaouimeryem@gmail.com \\ 4 Laboratory of Sustainability in architecture and urbanism, National School of Architecture, \\ Madinat Al Irfane Instituts, Rabat 10001, Morocco; laila.elghazouani@yahoo.fr \\ * Correspondence: Lahouari.Bounoua@nasa.gov
}

Received: 17 March 2020; Accepted: 8 April 2020; Published: 14 April 2020

\begin{abstract}
In Morocco, the last census counted $70 \%$ of houses in cities, with seven cities accounting for $25 \%$ of the total population and $41 \%$ of the urban population. This paper questioned the sustainability indicator in Moroccan cities using a novel methodology based on Earth observations and census data. We estimated the indicator for the 25 largest urban areas between 2003 and 2013. A stratification based on urbanization fractions allowed for the definition and comparison of hierarchically ordered zones consistent across urban areas and scales. We found no systematic pattern of growth between cities. However, three categories of development were identified: a group of large cities with an indicator less than unity and land consumption commensurate to population growth, a group of medium-sized cities trending moderately towards unsustainability with an indicator between one and two, and a group including small cities with significant departure from sustainability. The disparate sustainability levels between urban areas appear to be related to the rapid economic growth, typical of an emerging economy. Our results indicate a continuous population growth pushing outwards the perimeters of existing urban areas. Unless regulated, land consumption is increasing faster than the population in most parts of Morocco, in line with global trends.
\end{abstract}

Keywords: sustainable development goal; urbanization; Morocco

\section{Introduction}

In Morocco, the last census confirmed the polarization dynamics of the population around big cities, with a somewhat defined urban sprawl phenomenon. In 2014, the national number of houses amounted to 8.86 million units, of which 6.19 million (69.8\%) were in urban areas. Seven cities accounted for $25 \%$ of the total population and for $41 \%$ of the urban population [1]. This latest census, however, indicates that urban growth is mainly absorbed by cities' peripheries, which translates to a significant urban sprawl. This phenomenon is bound to last and intensify in the coming decades, due to rural exodus and the extension of urban perimeters. According to the Social, Economic and Environmental Council (SEEC), "the proportion of urban population will continue to grow in the coming decades to more than $70 \%$ by 2030 " [2].

Moroccan cities have high growth potential, particularly in terms of land use and verticality [3]. Future urban growth needs are estimated at 7000 ha/year by 2030 [4]. However, even Casablanca, the largest city in Morocco, populated by 3.3 million inhabitants, remains a medium-sized city compared 
to the metropolises of other emerging countries (for example, Kuala Lumpur has 7 million inhabitants, Istanbul 9 million, and Santiago 7 million). In Morocco, urban policies need to be greatly improved. An increasing number of households are forced to live in urban outskirts to take advantage of more moderate housing prices. However, these areas are generally underserved by public transit and only $23 \%$ of urban households own a private car [5].

Despite efforts to cover the territory, urban planning is still not a relevant and adapted tool to address environmental, economic, and social issues and regulate urban development as defined by the United Nations framework. Indeed, at its seventieth session, held on 25 September 2015, devoted to the post-2015 development agenda, the United Nations General Assembly (UNGA) adopted a program (2015-2030) on the worldwide framework for the implementation of 17 Sustainable Development Goals (SDGs) broken down into 169 targets [6], with SDG 11 dedicated to sustainable cities and communities. The 2030 Agenda has been accepted by all countries, which, according to the terms of the resolution, will have to adapt it to their specific needs while ensuring international comparison between countries.

The review of readiness for the implementation of the SDGs found that Morocco is clearly committed to implementing the 2030 Agenda and has a favorable constitutional and legislative framework to achieve these objectives.

At a time when Morocco needs to integrate the SDGs into its public policies, the Moroccan Social, Economic and Environmental Council addressed key questions for the success of Moroccan cities' sustainable transition, as part of a prospective study on the city of tomorrow [2]. The objective of the study was to identify the necessary factors to give metropolises and cities their sustainable renewal and extension, through the pillars of sustainability. However, the report makes no mention of examples of innovative urban solutions to make cities more accessible and sustainable in the context of limiting their sprawl.

In order to better engage in the implementation of the SDGs, a partnership on the support and follow-up of SDGs in Morocco was signed in January 2019 between the Office of the High Commissioner for Planning (HCP), the United Nations Development Program (UNDP), and 10 United Nations agencies (UNFEMMES, UNFPA, FAO, WHO, IOM, UNAIDS, UNESCO, UNHABITAT, UNECA, and UNICEF). This agreement is part of the UN Development Assistance Framework (UNDAF) 2017-2021. Its objective is to develop a reference framework for the monitoring and reporting of the SDGs in Morocco and to help inform policy makers and the public on national achievements in this area. In this context, Morocco has engaged in a national consultation, accompanied by UN agencies, on the implementation of the SDGs. This debate culminated in the organization of a national forum bringing together, among others, government departments, representatives of international organizations in Morocco, civil society, and experts in the field.

The analysis of urban growth is of capital importance for monitoring urban sustainability, as it allows an assessment of the past and directs future actions. Several studies have evaluated urban land consumption around the world but only few have assessed its sustainable development. For example, Shuqing Zhao et al. [7] questioned the spatiotemporal process of urban extension of several Chinese cities using Landsat data, and Soffianian et al. [8] used satellite images and visual interpretation to analyze urban extension and agricultural sprawl in Isfahan, Iran. Xiong et al. [9] assessed urban sprawl over large Indian cities with more than 1 million inhabitants and carried out an evaluation of sustainability using a multi-dimensional comparison analysis of urban expansion that considers growth rate, density, intensity, and landscape indices. On the other hand, Bounoua et al. [10] mapped the urban sustainability indicator from 2001 to 2011 and 2011 to 2020 over the conterminous United States, based on spatial projections of population and urban areas.

In Morocco only a few studies have assessed the impact of urban surface expansion and all were specifically aimed at assessing the impact of urban surface extension on surface climate, e.g., [11-14]. In this paper, we present for the first time a countrywide assessment of the UN SDG 11.3.1, an indicator of sustainability in urban areas. Specifically, the relationship between land consumption rate and 
population growth rate is estimated and analyzed for Morocco's 25 most populous urban areas, which also happen to be the largest, for the period 2003 to 2013, defined by the most recent available data.

\section{Method and Data}

The indicator 11.3.1 aims to monitor and measure sustainable urban development by comparing the rate of expansion of urban space with the rate of population growth during the same period. Its estimation requires the simultaneous assessment of the change in an urban surface area and in its population at different dates.

We estimated the SDG 11.3.1 using the Land Consumption Rate (LCR) and Population Growth Rate (PGR) using the UN defined methodology [15]:

$$
\begin{aligned}
& L C R=\frac{L N(U r b[t+\Delta t] / U r b[t])}{\Delta t}, \\
& P G R=\frac{L N(\operatorname{Pop}[t+\Delta t] / \operatorname{Pop}[t])}{\Delta t} .
\end{aligned}
$$

The SDG 11.3.1 was then estimated as the ratio of LCR to PGR, as:

$$
\begin{gathered}
L C R P G R=\frac{L C R}{P G R}, \\
L C R P G R=\frac{\operatorname{Ln}(U r b[t+\Delta t] / U r b[t])}{\operatorname{Ln}(\operatorname{Pop}[t+\Delta t] / \operatorname{Pop}[t])},
\end{gathered}
$$

where $L n$ represents the natural logarithm, $U r b[t]$ is the built-up surface area (surface units) during the initial year, and $U r b[t+\Delta t]$ is the built-up surface area during the future year. Similarly, Pop [t] is the total population (persons) in the initial year for each urban area and Pop $[t+\Delta t]$ is the total population of the same urban area in the future year; $\Delta t$ is the number of years between the two measurements.

Given its definition, SDG 11.3.1 presents some limitations:

1- It is not defined for a constant population between the two measurements,

2- It takes the value of zero if the urban area remains constant between the two measurements, and

3- It is unable to describe the dynamic of urban areas with a negative urban or population growth rate [16].

These singularities are not commonly found in urban and population data but are worth mentioning as they make the indicator unfit to capture and comprehend the coupled dynamic of land consumption and population change. It is important to note that the data used for this study did not correspond to any of these limitations (see Section 2.2).

The methodological approach to evaluate SDG 11.3.1 in this study consisted of two steps. The first included estimation of the urban surface area delimitation and size, the second step estimated the population within the urban surface area.

There is no internationally agreed upon definition of an "urban area" and trying to accurately define it is a delicate task. As stated by the United Nations [17], "because of national differences in the characteristics that distinguish urban from rural areas, the distinction between the urban and the rural population is not yet amenable to a single definition that would be applicable to all countries or, for the most part, even to the countries within a region. Where there are no regional recommendations on the matter, countries must establish their own definitions in accordance with their own needs".

\subsection{Assessment of the Urban Area Size}

In this study, the assessment of buildup in urban areas was performed using satellite data, following Diksha and Kumar [18], Li et al., [19], and references therein. The dynamic of the urban extent at fine spatial resolution over large areas is necessary for developing urban growth models 
and monitoring sustainable development goals. However, there are limitations in mapping urban dynamics, and the most recent study by Li et al. [19] provides a complete description.

The objective of this step was to define and assess the urban areas' sizes in the study region. To do so, we used 48 Landsat- 8 scenes at $30 \mathrm{~m} \times 30 \mathrm{~m}$ horizontal resolution for the year 2013 and 48 Landsat-7 scenes at the same resolution for the year 2003 from the US Geological Survey (USGS) to cover the study area-Morocco (Figure 1). These years were chosen because of the availability of cloud-free satellite images and were the closest in time to Morocco's census years, 2004 and 2014. These datasets were then used to differentiate artificial surfaces — urban surfaces areas (USA) — from natural surfaces (vegetated, bare, and water bodies) for the two years over Morocco. We used Geographic Information System (GIS)-based spatial analysis for all pretreatments and a supervised classification to map urban areas over the study region [14].

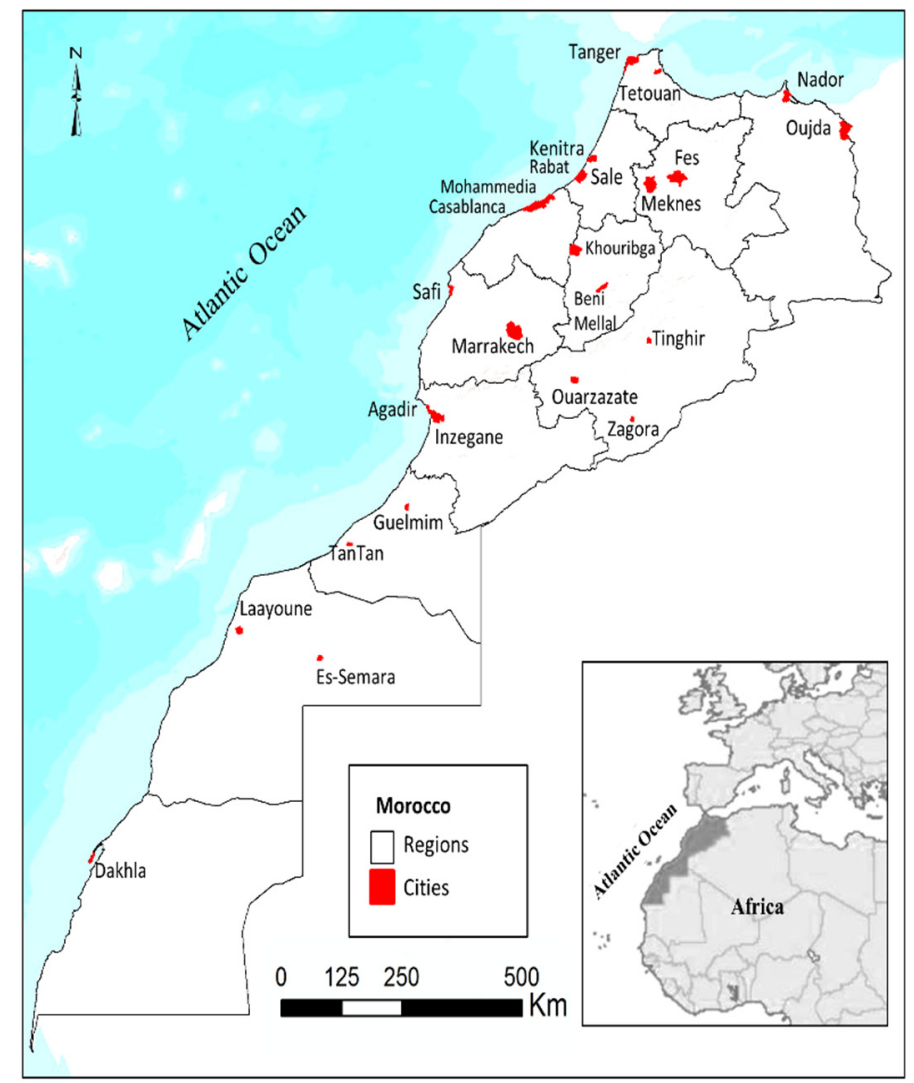

Figure 1. Study region showing the 25 urban areas selected for this analysis (see text for details).

We applied a correction to extract atmospheric effects from observations [20] and used the corrected data within a supervised maximum likelihood classifier (ML) in which a pixel is assigned to a class according to its probability of belonging to that particular class [21]. Before the classification process, four classes (urban, vegetation, water, and bare soil) were defined in order to avoid confusion between classes that have similar reflectance and to distinguish the transition between the built and the natural environment [14]. For that, we created two sets of regions of interest (ROI) as training regions for the four classes by digitizing polygons based on high-resolution images from Google Earth, and onsite observations where available; one set was used for the classification and the other for validation. Three to four hundred samples, depending on the composition of scenes, spread across the region and classes were used. The confusion matrix and visual analysis were used to assess the final classification's quality. Overall, the classification presented an accuracy between $80 \%$ and $98 \%$ over the 48 scenes [14].

Between the census years 2004 and 2014, Morocco's administrative division changed from 16 regions to 12 regions, with municipalities and towns redistricted for socio-economic considerations. This redistricting made it impossible to compare the same urban area and its population over a period 
based solely on its administrative boundary. In order to avoid this obstacle, we developed an objective method based on satellite Earth Observations (EO) to delineate "urban areas". An urban area here refers to an urban conurbation-a large urban cluster where the zones of influence of distinct cities or towns are connected by a quasi-continuous built-up development. Each city or town in a conurbation may, however, be an independent unit.

To do so, we selected large conurbations around known urban areas and perform a supervised classification at $30 \mathrm{~m} \times 30 \mathrm{~m}$ spatial resolution using the Landsat data to discriminate between manmade urban surfaces and all other classes (Figure 2a). We then aggregated all impervious pixels from $30 \mathrm{~m} \times$ $30 \mathrm{~m}$ to $1 \mathrm{~km} \times 1 \mathrm{~km}$ spatial resolution and expressed the urban surface area (USA) as a fraction of the $1 \mathrm{~km} \times 1 \mathrm{~km}$ pixel (Figure 2b). Next, we stratified each urban cluster into three zones based on the USA fraction in each $1 \mathrm{~km}$ pixel. The stratification started from the highest USA fraction in the core of the urban conurbation and proceeded outward, defining an urban zone containing all pixels with USA fractions greater than or equal to $25 \%$, and a suburban zone containing all pixels with USA less than $25 \%$ but greater than or equal to $5 \%$. Pixels containing less than $5 \%$ USA were considered rural. When defining rural zones using this method, care was taken not to infringe into suburban or urban zones of neighboring urban areas, if any, by limiting their extent within a buffer zone of $20 \mathrm{~km}$ from the $5 \%$ USA contour. The final delimitation of the urban area was ultimately obtained by including all administrative units containing pixels with more than 5\% USA and included in the population census (Figure 2c). This definition provided an objective basis for the evaluation and comparison of SDG 11.3.1, if the same urban area was used at both the initial and future time steps. This stratification followed that of Imhoff et al. [22], but differed from it in terms of thresholds of USA delimiting the different zones and the number of zones. Instead of five zones, as in Imhoff et al. [22], we opted for a simplified three-zone stratification, which corresponded better to the size of the urban areas of the study region. In Morocco, urban areas are generally formed by small, disorganized cities and towns with no clear distinction between the urban cores and the suburbs. In fact, the suburbs appear as natural extensions of the urban cores. By contrast, there is a clear distinction between the edges of the suburbs and rural zones, characterized by pixels with USA less than $5 \%$. The total USA within the urban area was then assessed. For example, for what is administratively known as the urban area of Tanger-Assilah, a large proportion of the population is concentrated in the 'commune urbaine', including the arrondissements of Tanger-medina, Charf-Souani, Charf-Medghogha, Beni Makada, and the municipality of Gueznaya (Figure 2c).

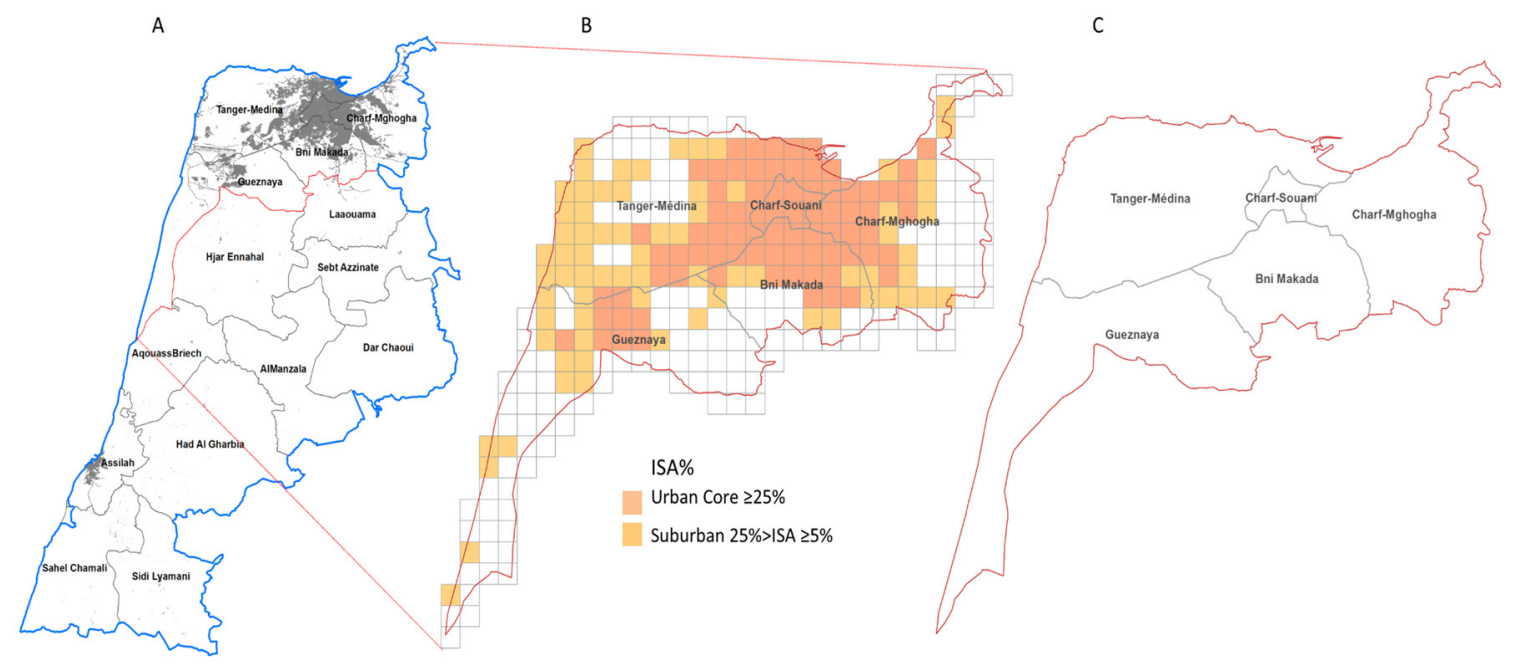

Figure 2. Definition of the urban area of Tangier using satellite data. (A) Administrative limits of the urban conurbation (blue) where the grey dots represent the urban surface area classification at $30 \mathrm{~m} \times 30 \mathrm{~m}$ and the dashed contours represent the limits of census units (towns). (B) Aggregation of the urban surface area from $30 \mathrm{~m} \times 30 \mathrm{~m}$ to $1 \mathrm{~km} \times 1 \mathrm{~km}$ and delimitation of the urban zones. (C) Census units with urban surface area greater than $5 \%$ (see text for details). 
We applied this stratification to the entire country, which resulted in 140 urban areas, from which we selected the 25 largest for this analysis (Figure 1).

\subsection{Assessment of the Urban Area Population}

The SDG 11.3.1 indicator's definition has an underlying requirement for a uniform collection of both an urban area size and its population across spatial and temporal scales in order to allow for an objective monitoring of urban development sustainability and its inter-comparison between urban areas.

The objective of this section is to assess the population count in each of the urban areas defined above. To estimate the population of 2003 and 2013 from those of 2004 and 2014, we performed a linear interpolation using the 10-year average growth rate for each of the 25 urban areas. This constrained the total population change between 2003 and 2013 to be the same as that of the period 2004-2014. For all the urban areas, the overall urban growth rate was $1.9 \%$, slightly higher than the countrywide population growth rate of $1.4 \%$ during the same period [23]. We followed the delineation performed in Section 2.1 and assembled its population for the municipalities it included. For example, for the Tangier urban area, we added the population of the five municipalities included in the selected urban area (Table 1). This procedure was repeated for the 25 urban areas of Morocco with the largest urban core. Results are illustrated in Figure 3.

Table 1. Tangier urban area population for years 2003 and 2013 (persons).

\begin{tabular}{cccc}
\hline \multirow{2}{*}{$\begin{array}{c}\text { Urban } \\
\text { Area }\end{array}$} & Arrondissements/Municipalities & $\mathbf{2 0 0 3}$ & \multirow{2}{*}{$\mathbf{2 0 1 3}$} \\
\hline \multirow{3}{*}{ Tangier } & Tanger-médina & 166,634 & 235,067 \\
\cline { 2 - 4 } & Charf-Souani & 115,660 & 117,455 \\
\cline { 2 - 4 } & Charf-Medghogha & 136,159 & 194,439 \\
\cline { 2 - 4 } & Beni Makada & 223,851 & 369,158 \\
\cline { 2 - 4 } & Gueznaya & 1176 & 21,287 \\
\hline
\end{tabular}

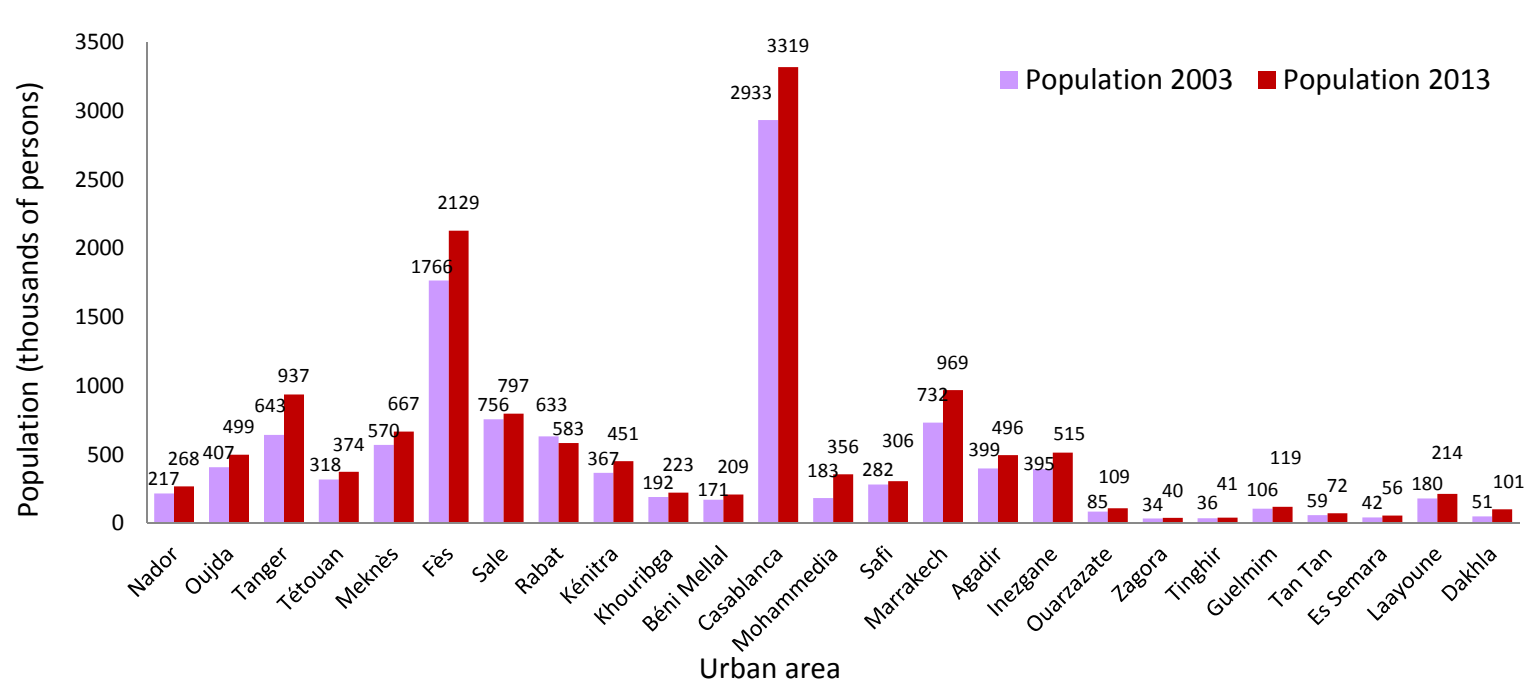

Figure 3. Population count for the 25 urban areas selected for this study, for 2003 and 2013.

\subsection{Computation of the Sustainability Indicator}

The urban sustainability indicator SDG 11.3.1 was computed using Equation (4). For comparison, we also estimated changes in the USA per capita, as defined by Bounoua et al. [24], and compared its variation to SDG 11.3.1. 


\section{Results and Discussion}

The urban sustainability indicator SDG 11.3.1 was computed using the UN formulation given by Equation (4). The USA included all impervious surfaces used in urban settings, such as parking lots, roads, highways, buildings, driveways, sidewalks, playgrounds, and all other manmade surfaces, and was estimated using satellite data. As defined, the indicator implies that urban areas with SDG 11.3.1 values less than one indicate that land consumption is happening at a slower rate than population growth and thus are on the sustainable side. On the other hand, values greater than one are indicative of urban areas growing faster than population and suggest movement away from sustainability. A value of one would theoretically indicate that land consumption rate is commensurate to population growth rate, and if maintained, the urban area would maintain its original sustainability level. As noted in Bounoua et al. [16], the indicator has difficulties describing a situation with decrease in urban area or population. In our study region, among the 25 urban areas, only Rabat had undergone a reduction in its population between 2003 and 2013 and therefore its SDG indicator was not included in the analysis. Indeed, Rabat is characterized by a weak migratory inflow, which involves all regions of Morocco without a clear predominance. However, a significant outflow, about $21 \%$, is noted from Rabat, resulting mostly in the spilling of its population over to Salé and other neighboring towns, in search for more affordable housing [25]. For comparison, we utilized a quantifiable measure, the USA per capita (USA/cap), and used its variation as a metric to parallel the SDG 11.3.1. The USA/cap is a state variable defined as the urban surface area (USA), obtained from satellite observation, divided by the population total of the same area at given time and therefore provides an actual urban land consumption of each individual [26].

Results of the SDG indicator are presented in Figure 4 and are sorted from smallest to largest values to facilitate an inter-urban area comparison. The smallest SDG was recorded in the urban area of Mohammedia, with a value of only 0.41 . The sustainability indicator of this emerging urban area suggests that during the decade 2003-2013, the land consumption rate for urban purposes represented $41 \%$ of the population growth rate. To better comprehend the meaning of this indicator, we compared it to change in the actual urban land use per capita (USA/cap), which indicated that, during the same period, land consumption decreased by $41.9 \mathrm{~m}^{2}$ per person (Table 2). Both the SDG and the USA/cap metrics point to the fact that the urban area of Mohammedia is moving towards sustainability. However, because the indicator does not inform about the intrinsic level of sustainability [16] these results only suggest progress towards sustainable land use relative to the initial condition. However, if the initial condition was sustainable to begin with, a decline in urban land use per capita may result in unsustainable overcrowding. As of 2013, Mohammedia had an USA/cap of $87.8 \mathrm{~m}^{2} /$ person (Table 2). Despite recent efforts to build vertically, the decadal change in urban surface area indicated a largely peripheral urban growth, and although at a much smaller rate than population increase, resulted in significant urban sprawl (Figure 5). If not regulated, this phenomenon is bound to intensify in the coming decades due to increase in urban population and further extension of the urban perimeters. 
Table 2. Urban surface area, Population, SDG 11.3.1, and urban surface area per capita for the 25 urban areas and for 2003 and 2013.

\begin{tabular}{|c|c|c|c|c|c|c|c|c|}
\hline \multirow[b]{2}{*}{ Urban Area } & \multicolumn{2}{|c|}{ Urban Surface Area (ha) } & \multicolumn{2}{|c|}{ Population (persons) } & \multirow{2}{*}{$\begin{array}{c}\text { SDG 11.3.1 } \\
\text { Indicator } \\
\end{array}$} & \multicolumn{2}{|c|}{ USA per Capita $\left(\mathrm{m}^{2} /\right.$ person $)$} & \multirow{2}{*}{$\begin{array}{c}\text { USA per Capita } \\
\text { Difference } \\
\end{array}$} \\
\hline & 2003 & 2013 & 2003 & 2013 & & 2003 & 2013 & \\
\hline Rabat & 1934.91 & 4581.27 & 632,873 & 583,462 & NA & 30.6 & 78.5 & 47.9 \\
\hline Mohammedia & 2376.72 & 3123.36 & 183,269 & 355,636 & 0.41 & 129.7 & 87.8 & -41.9 \\
\hline Casablanca & $15,390.81$ & $16,997.04$ & $2,933,433$ & $3,318,651$ & 0.80 & 52.5 & 51.2 & -1.3 \\
\hline Marrakech & 7206.93 & 9878.67 & 732,166 & 968,727 & 1.13 & 98.4 & 102.0 & 3.5 \\
\hline Dakhla & 302.85 & 726.39 & 50,552 & 101,211 & 1.26 & 59.9 & 71.8 & 11.9 \\
\hline Inezgane & 1991.07 & 2933.82 & 394,721 & 514,630 & 1.46 & 50.4 & 57.0 & 6.6 \\
\hline Nador & 2192.13 & 3011.58 & 216,736 & 267,972 & 1.50 & 101.1 & 112.4 & 11.2 \\
\hline Tanger & 3001.5 & 5505.84 & 643,479 & 937,405 & 1.61 & 46.6 & 58.7 & 12.1 \\
\hline Tinghir & 598.68 & 776.61 & 35,826 & 41,479 & 1.78 & 167.1 & 187.2 & 20.1 \\
\hline Oujda & 3413.16 & 4972.14 & 407,299 & 499,248 & 1.85 & 83.8 & 99.6 & 15.8 \\
\hline TanTan & 433.08 & 623.34 & 59,447 & 71,958 & 1.91 & 72.9 & 86.6 & 13.8 \\
\hline Zagora & 313.83 & 426.87 & 34,329 & 39,545 & 2.17 & 91.4 & 107.9 & 16.5 \\
\hline Laayoune & 1043.1 & 1527.48 & 180,287 & 214,328 & 2.21 & 57.9 & 71.3 & 13.4 \\
\hline Agadir & 2534.49 & 4199.67 & 398,831 & 495,648 & 2.32 & 63.5 & 84.7 & 21.2 \\
\hline Guelmim & 673.56 & 912.06 & 106,062 & 119,406 & 2.56 & 63.5 & 76.4 & 12.9 \\
\hline Béni Mellal & 1083.06 & 1873.71 & 171,424 & 208,720 & 2.78 & 63.2 & 89.8 & 26.6 \\
\hline Tétouan & 887.04 & 1407.69 & 318,364 & 374,289 & 2.85 & 27.9 & 37.6 & 9.7 \\
\hline Kénitra & 1686.78 & 3116.97 & 366,953 & 451,467 & 2.96 & 46.0 & 69.0 & 23.1 \\
\hline Fès & 3048.21 & 5629.23 & $1,765,742$ & $2,129,094$ & 3.28 & 17.3 & 26.4 & 9.2 \\
\hline Ouarzazate & 671.04 & 1707.84 & 85,111 & 108,875 & 3.79 & 78.8 & 156.9 & 78.0 \\
\hline Es Semara & 190.71 & 568.08 & 42,074 & 55,725 & 3.88 & 45.3 & 101.9 & 56.6 \\
\hline Khouribga & 1260.45 & 2322.18 & 191,724 & 222,712 & 4.08 & 65.7 & 104.3 & 38.5 \\
\hline Meknès & 2500.38 & 5945.13 & 570,068 & 666,877 & 5.52 & 43.9 & 89.1 & 45.3 \\
\hline Sale & 2228.13 & 3594.96 & 756,063 & 797,298 & 9.01 & 29.5 & 45.1 & 0.6 \\
\hline Safi & 766.26 & 1721.79 & 282,374 & 306,132 & 10.02 & 27.1 & 56.2 & 29.1 \\
\hline
\end{tabular}

Note: NA: Not Applicable. 


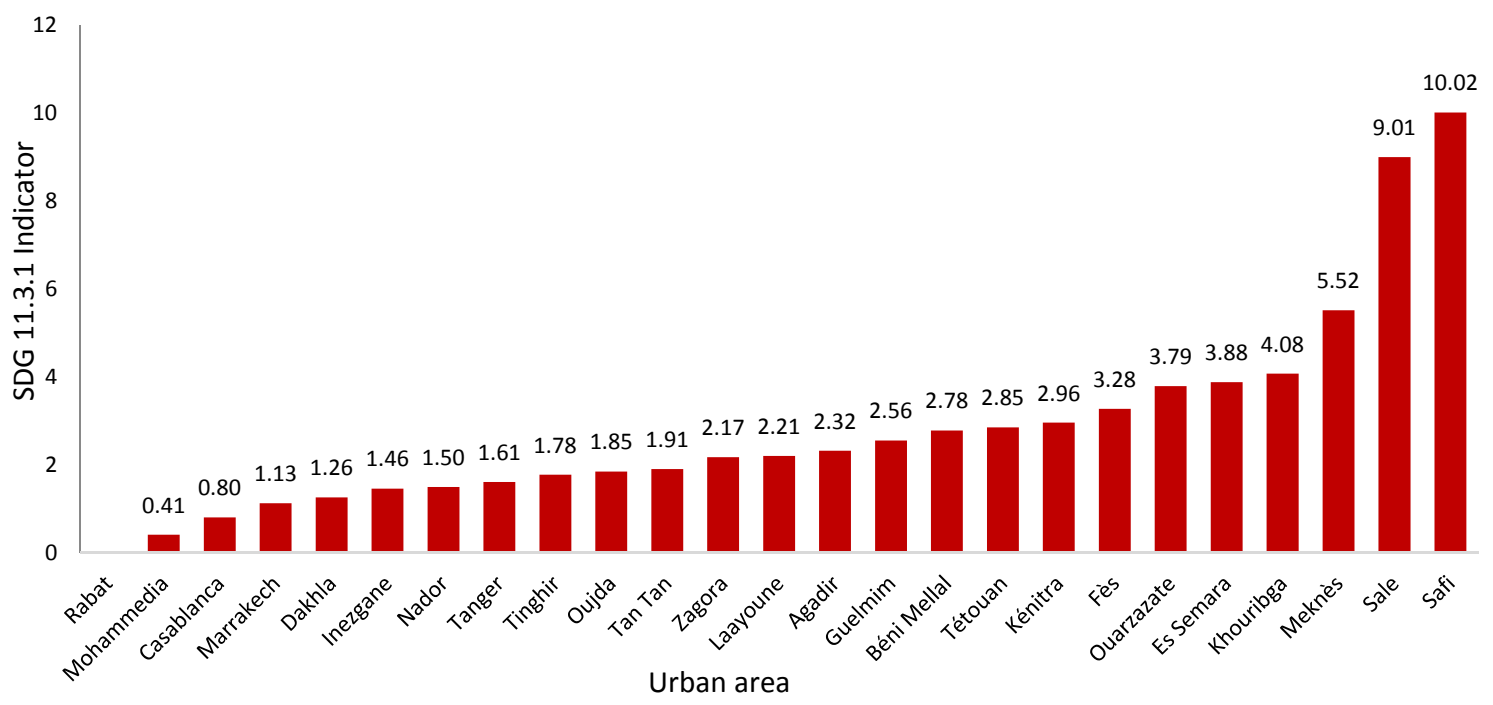

Figure 4. Sustainable Development Goal (SDG) 11.3.1 for the 25 selected urban areas.

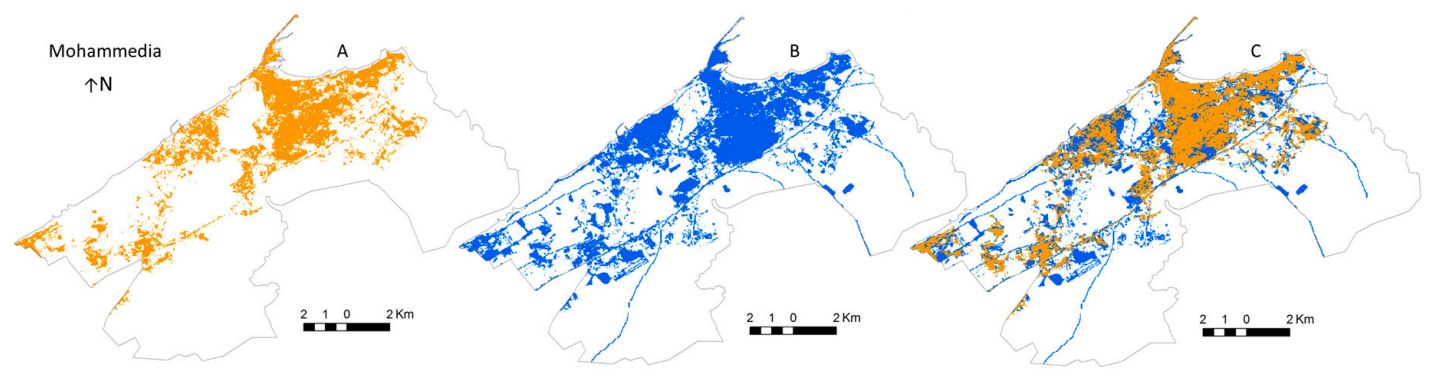

Figure 5. Urban surface area for the conurbation of Mohammedia (see Figure 1 for location), (A) 2003, (B) 2013, and (C) change from 2003 (orange) and 2013 (blue).

The analysis of Mohammedia conurbation's development indicated that the extension took place in a southwestern-northeastern direction around the existing constructions and along the coastal front approaching the ecological city of Zenata. In the South and extreme West, urbanization was developed along provincial roads, while the northern and central areas were saturated during this decade. Each of these new extension areas is characterized by a specific morphology and mode of occupation, which clearly affects the desired sustainability objectives for this conurbation with a great industrial past. Thanks to its proximity to the two metropolises of Rabat and Casablanca and its good motorway access, Mohammedia has offered a housing market with good stands. Residential buildings are emerging in the urban landscape, are presented in a well-kept setting, with respected prospect widths, green spaces, and heights not exceeding $20 \mathrm{~m}$. Moving away from the urban perimeter, urbanization follows a logic of peri-urban housing estates forming rows of "modern Moroccan houses" with a footprint around $65 \mathrm{~m}^{2}$, with the ground floor reserved for commercial function and the upper floors for housing, without any search for harmony or urban continuity.

On the other hand, Casablanca, the most populous urban area of Morocco, ranked second in terms of sustainable development, with an SDG 11.3.1 value of 0.80 , suggesting sustainability. Like Mohammedia, over the ten-year period, the USA/cap change in Casablanca decreased, but by a much smaller amount of $1.3 \mathrm{~m}^{2}$ per person (Table 2). This result appears realistic and revealing of the high demand for urban land in the largest Moroccan economic metropolis. Located on the western coast of Morocco, Casablanca is attractive for its moderate climate and business activities. This economic capital is developing fast and many homes, offices, and business districts are being built, making its real estate amongst the most expensive in Morocco and enticing its population to spill over to Mohammedia, not more than $25 \mathrm{~km}$ away. In Casablanca, the decadal per capita land use changed from $52.5 \mathrm{~m}^{2} /$ person in 
2003 to $51.2 \mathrm{~m}^{2} /$ person in 2013. This confirms the trend towards sustainability established by SDG 11.3.1 and indicates that the urban sprawl is under control. The use of vertical structure for housing and offices is possibly contributing to a reduced footprint with dense zones in the urban center (Figure 6a). During this decade, Casablanca's evolution followed two trends: the densification of the center and the coastal front, and the spread towards the periphery. The densification of the center was achieved by reinvesting urban wastelands in a context of great covetousness of land in the city center, whereas the sprawl along the coast accommodated residential as well as commercial and leisure functions. Large tracts of land are reserved for malls, hotels, shopping centers, and luxury residences, thus forming an ecosystem of exclusion and social marginalization.

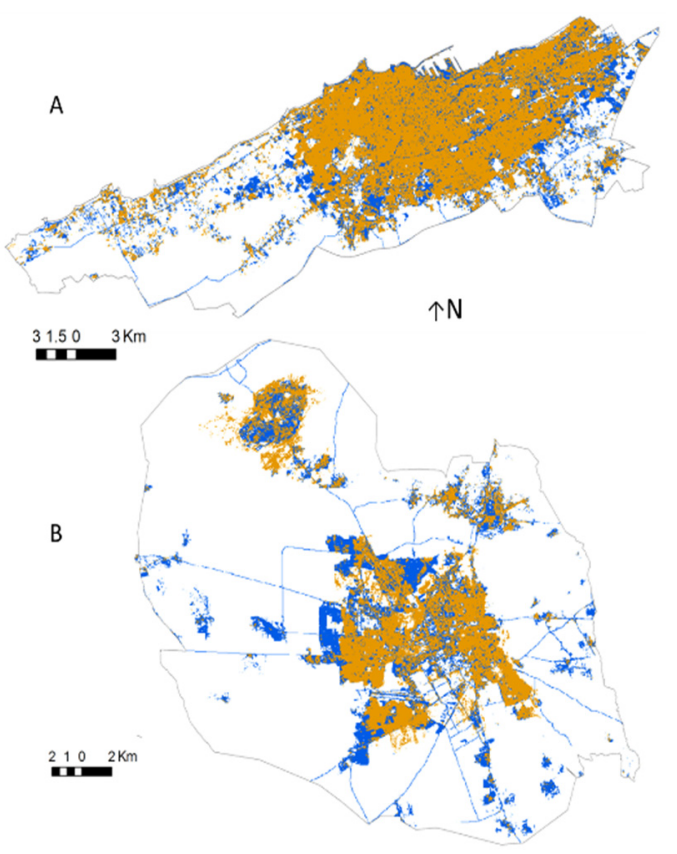

Figure 6. Spatial extent of urban surface area for (A) Casablanca and (B) Marrakech. Orange represents the area in 2003 and blue the area in 2013.

The mode of extension towards the outskirts of the city has been through large resettlement complexes for shantytowns or social housing within the framework of the national plan for the revival of housing. The occupation noted is industrial because of the development of the East industrial zone during this decade. It is important to note that the new urbanization to the East belongs to the ecological city of Zenata, where sustainability, environmental awareness, and social mix have been the founding principles.

Marrakech, the iconic Moroccan city in the center of the country, with a population of 968,727 people ca. 2013, has seen its urban area increased by 2672 ha for an increase in population of 236,561 persons. With a sustainability indicator of 1.13 , just over the neutral value, Marrakech appears to be slightly drifting away from a sustainable development pathway. Because of its location confined in a semi-arid region with oases juxtaposed to a snowy mountain with the highest African summit, Marrakech has attracted foreign residents and land investors, in addition to an increasing number of tourists. While some of the newcomers settle in the old Medina and refurbish 'Riyadhs' (old buildings with a millennial culture and history), most visitors prefer western-style dwellings in large and modern buildings. This has prompted the construction of several luxury hotels, malls, and other leisure and business venues. With such an urban expansion comes infrastructure development, such as roads, parking, and multiple transportation means occupying a fair amount of urban space. In face of this situation, particular to Marrakech, special attention needs to be paid to the utilization of urban land in order to maintain or improve sustainability. Unlike Casablanca and Mohammedia, which are limited by the ocean, Marrakech conurbation is sprawling away from the center in a concentric pattern where 
construction in the suburbs is consuming urban land at a rate slightly faster than population growth (Figure 6b). By 2013 Marrakech had a USA/cap of $102.0 \mathrm{~m}^{2} /$ person, or an increase of $3.5 \mathrm{~m}^{2} /$ person, compared to 2003 (Table 2). These data do not include the numerous tourists visiting the city, which by some accounts were over 2 million in 2017 [27]. Marrakech has been subject to great densification and urban sprawl during this decade, especially its western periphery, marked by large residential developments. The density and degree of development is much contrasted. Concerning the areas of environmental interest, the olive grove has been preserved against construction. However, the vast palm grove was a victim of its great tourist success and has been replaced by rapid urbanization, characterized by golf courses, houses, and hotels-so many actions that harm the environmental balance of this millennial ecosystem.

The relative control and management in urban land consumption in Morocco's largest urban areas may be the outcome of important government programs aimed at managing urban space. Indeed, starting in the mid-nineties, Morocco implemented a series of social programs aiming at reducing rural poverty and curbing rural exodus, which led to stabilizing the rapid urbanization. However, despite the success in reducing rural movements, urban demography has increased, and urban management is still a challenge [27]. The adoption of a national chapter for planning and sustainable development has ultimately resulted in the fusion of several operators into a single planning group to meet the challenge of social housing and urban upgrade within a sustainable development framework. This has had a significant impact on urban land management, especially in large urban areas such as Casablanca and Marrakech which, despite a high increase in population between 2003 and 2013, have maintained an SDG indicator close to unity. The same cannot be said about Tangier and Fes, two other large urban metropolises, where the SDG indicator is 1.61 and 3.28, respectively, and where urban land use needs to be regulated in order to reverse the unsustainable development trend recorded during the 2003-2013 decade.

An exception to all large urban areas of Morocco is Rabat, which, between 2003 and 2013, recorded an increase in impervious area of about $27 \mathrm{~km}^{2}$, but lost 49,411 of its population, a loss close to the gain in population of 41,235 people recorded in Salé. Among the 25 largest urban areas considered in this analysis, only two have an SDG indicator less than unity, Mohammedia and Casablanca, and two others have it close to unity, Marrakech and Dakhla. Of these four urban areas, three are considered relatively large in terms of both their urban surface area and population. The fourth one, Dakhla, is a small coastal urban area located in the extreme South of Morocco (Figure 7) with a USA of about 3 $\mathrm{km}^{2}$ as of 2003 (Table 2). However, between 2003 and 2013, Dakhla recorded an increase in size of $140 \%$ to reach $7.26 \mathrm{~km}^{2}$ in 2013 for a $100 \%$ increase in population. It is a growing tourist region with a relatively small population and, with an SDG indicator of 1.26, seems to be consuming its urban land faster than its population growth, therefore trending away from sustainability. In terms of spatial extent, Dakhla has reshaped its landscape; it turned away from the existing urban center in the bayside to spread out on the Atlantic coast. Sprawl was achieved by the development of the subdivision of the industrial zone and by the emergence of new districts. Dakhla chose an urban morphology in the form of a checkerboard pattern for high density and a mainly residential function.

Aside from these four urban clusters, the analysis showed a group of small to moderate size (4 to $30 \mathrm{~km}^{2}$ in 2003) urban areas, Inezgane, Nador, Tangier, Tinghir, Oujda, and TanTan, which are consuming land at a rate between one and a half to slightly less than two times the rate of population increase (1.5 SDG 11.3.1 2.0), pointing to non-sustainable development. The SDG indicator for all remaining urban areas analyzed in this study is greater than two (SDG 11.3.12.0), indicating a significant departure from sustainability (Figure 4). Two extreme cases were, however, observed in the urban areas of Salé and Safi with SDG indicators of 9.01 and 10.02, respectively. The urban area of Salé appears to absorb the population overflow from Rabat in addition to accommodating its own population growth. It has also welcomed new industrial zones, companies' headquarters, as well as exhibition halls and department stores that have pushed an area increase of $13.7 \mathrm{~km}^{2}$ and a USA per capita increase of $15.6 \mathrm{~m}^{2} /$ person. Similarly, the urban area of Safi has seen its urban surface area increase by $9.55 \mathrm{~km}^{2}$ 
while its USA per capita went up by $27.1 \mathrm{~m}^{2}$ /person to $56.2 \mathrm{~m}^{2}$ in 2013 , due mainly to industrial development, including the expansion of the port.

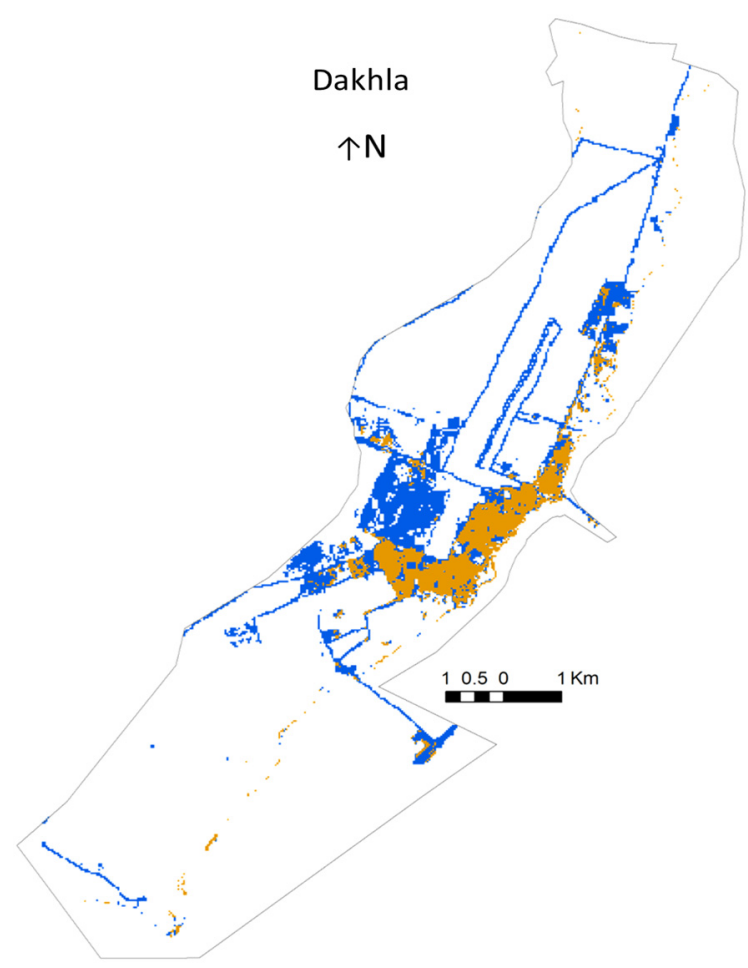

Figure 7. Spatial extent of urban surface area for Dakhla for 2003 (orange), 2013 (blue).

The fact that the largest population changes were observed in urban areas which did not exhibit the highest USA growth, such as in Casablanca and Mohammedia, is an indication that these urban centers are using small surface footprints to accommodate for their population growth and possibly expanding vertically in high-density zones. Urban surface area per capita appears as another useful indicator for monitoring land use change. When considering all 25 urban areas across scales within the country, we noted that most of them had a USA/cap increase between 3 and $20 \mathrm{~m}^{2} /$ person, except Agadir, Beni Mellal, Kenitra, Khouribga, and Safi, which experienced an increase between 20 and $30 \mathrm{~m}^{2} /$ person, and Rabat, Ouarzazate, Es Samara, and Meknes, which increased by more than $40 \mathrm{~m}^{2} /$ person. Ouarzazate showed a record increase of $78 \mathrm{~m}^{2} /$ person. On the contrary, Casablanca and Mohammedia showed a decrease in USA/cap. In these two urban areas, increase in population does not necessarily translate to urban expansion but rather to increase in population density and possible use of vertical structures with small footprints.

The large discrepancies between urban areas in term of USA/cap could be a consequence of several factors, including geographic limitations such as a mountain or sea, land regulation, land value, and cultural preference, whereby people prefer to build horizontally. This makes the analysis of urbanization dynamics a challenge [28] and calls for a regionally adapted, consistent regulation of land use in urban areas. This challenge is illustrated using the three urban areas of Casablanca and Oujda, which have relatively similar urban surface area growth, and Oujda and Meknes, which have similar population growth (Figure 8). Variations in these urban areas indicate that even if the increase in population can be similar for different urban centers, their changes in urban surface area, a proxy for urban expansion, may differ. For example, Meknes and Oujda had similar population increases but had noticeably different increases in urban surface area. On the other hand, for a population growth 4.2 times larger in Casablanca than in Oujda, these two urban centers showed about the same increase in urban surface area. The urban dynamic in Meknes showed a higher decadal increase in urban surface area per capita, $45.3 \mathrm{~m}^{2} /$ person compared to $15.8 \mathrm{~m}^{2} /$ person in Oujda and a decrease of 
$1.3 \mathrm{~m}^{2} /$ person in Casablanca. These results are in line with global findings reported by the U.N. in its Report of Goal 11 in 2019, which indicates that urban areas are expanding at a faster rate than their populations. The report also states that between 2000 and 2014, urban areas grew 1.28 times faster than their populations and suggests that the urban densities have declined, creating repercussions for environmental sustainability at the local, regional, and global scale [29].

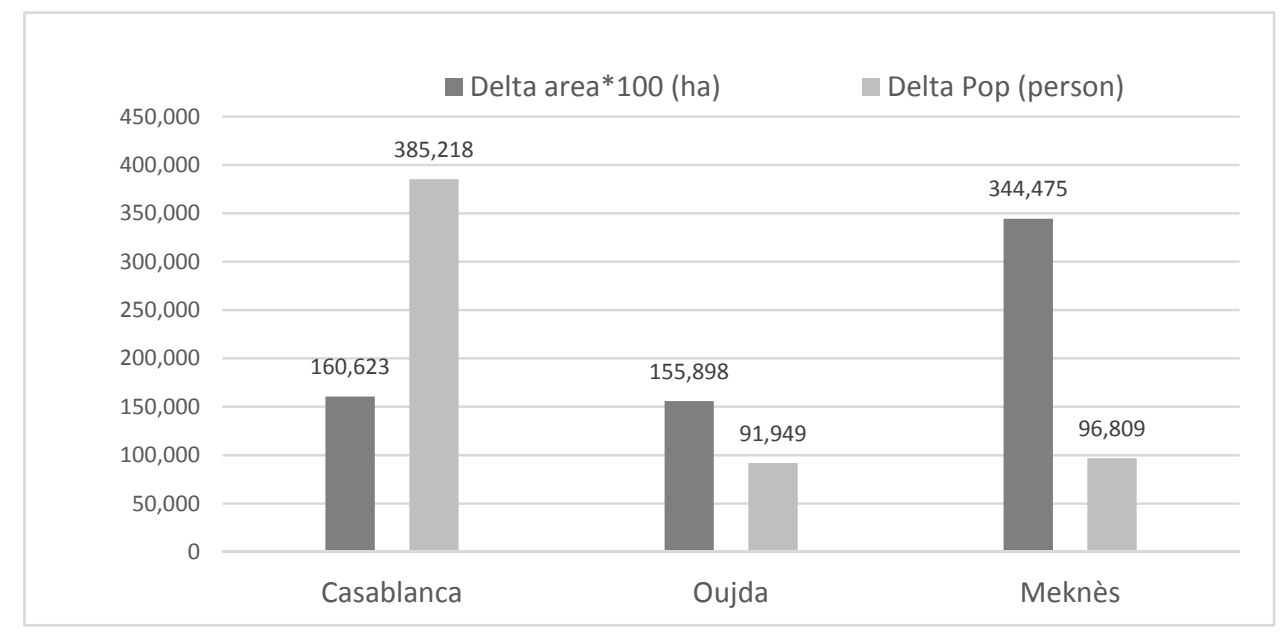

Figure 8. Population changes (persons) and urban surface area (ha) (Multiplied by 100 for plotting purpose) for Casablanca, Oujda and Meknes between 2003 and 2013.

\section{Concluding Remarks}

Landsat-based data and a supervised classification were used to map urban surface areas in Morocco. Combined with detailed demographic information, the urban land use data provided for the computation of the urban sustainability development indicator. The definition of the urban surface area was strictly based on satellite data within the limits of administrative units with available census information. A stratification based on urban surface area allowed the definition of hierarchically ordered zones that were consistent across urban areas and across scales and allowed for an inter-comparison of the sustainability indicator for the 25 largest urban areas of Morocco between 2003 and 2013. We found no systematic pattern of urban growth, but three categories of urban development were identified. The first category, with a sustainable development indicator close to unity, had a land consumption rate commensurate with its population growth and therefore maintained its level of sustainability, or otherwise trended towards it. Most of the urban areas falling in this category were relatively large and experienced a decadal reduction in urban surface area per capita. A second category of urban areas with moderate size displayed a sustainability indicator between 1.5 and 2, associated with an increase in per capita land use ranging between 6 and $17 \mathrm{~m}^{2} /$ person, indicating a trend towards unsustainable urban land consumption. The third category exhibited significant departure from sustainability and included extreme cases in small urban areas where the SDG indicator suggested a great difference between urban land consumption and population growth. This discrepancy between the rate of growth of urban land consumption and population dynamic is partly because Morocco is an emerging country in full development with a remarkable industrialization and infrastructure growth. With a tourist-based economy, Morocco has undergone an unprecedented urban expansion to accommodate more than 11 million tourists in 2017. This number, along with local population increase, is poised to grow and push outward the perimeters of existing urban spaces. Urban areas' sustainability or the ability to accommodate a population increase without overcrowding, depleting resources or compromising future growth, depends on whether they harness the efficiency gains from past urban land management. Despite the importance of the efforts devoted to the urban sector, the solutions provided appear still insufficient for the challenges ahead, and if not monitored closely and regulated, urban land consumption may be a future challenge in Morocco. While the sustainability 
indicator does not provide an intrinsic level of sustainability, it does nevertheless capture the variation from it, a variation that closely parallels that of the urban surface area per capita. Urban science research is receiving increasing traction and our knowledge about population and urban land use dynamics is questioning both the sustainability of this dynamic and its impact on the environment and human well-being.

Author Contributions: Conceptualization, L.B. and M.M.; methodology, L.B., N.F. and M.E.B.; software, L.B., N.F., and M.E.B.; validation, M.E.B., N.F., and L.E.G.; formal analysis, L.B., N.F., M.E.B., M.M. and L.E.G.; investigation, L.B. and M.M.; resources, L.B., M.M.; data curation, N.F., M.E.B.; writing-original draft preparation, L.B.; writing—review and editing, L.B., M.M., L.E.G., N.F. and M.E.B.; visualization, M.E.B., N.F.; supervision, L.B.; project administration, L.B. and M.M. All authors have read and agree to the published version of the manuscript.

Funding: This research received no external funding.

Conflicts of Interest: The authors declare no conflict of interest.

\section{References}

1. Haut-Commissariat au Plan. Répartition Géographique de la Population d'Après les Données du Recensement Général de la Population et de l'Habitat de 2014. Available online: https://www.hcp.ma/Repartition-geographique-de-la-population-d-apres-les-donnees-du-RecensementGeneral-de-la-Population-et-de-l-Habitat-de_a1796.html (accessed on 2 April 2020).

2. Sustainable Energy and Environmental Challenges. Réussir la Transition vers des Villes Durables: Avis du Conseil Économique, Social et Environnemental (CESE). Available online: http://www.ces.ma/Documents/ PDF/Auto-saisines/2017/as32-2017-villes-durables/Av-AS32-VF.pdf (accessed on 3 April 2020).

3. Chauffour, J.-P. Le Maroc à l'Horizon 2040: Investir dans le Capital Immatériel Pour Accélérer L'émergence Economique; La Banque mondiale: Washington, DC, USA, 2018. [CrossRef]

4. Banque Mondiale. Note Thématique Pour une Nouvelle Stratégie de Mise en œuvre et de Gouvernance de L'urbanisme et de L'aménagement Urbain Défis, Contraintes et Leviers D'action Revue de L'urbanisation au Maroc (Projet p164989). Available online: http://documents.worldbank.org/curated/en/ 673611540331013534/pdf/AUS0000240-REVISED-180607-MUR-Planning-Thematic-Note-final-clean.pdf (accessed on 3 April 2020).

5. Haut Commissariat au Plan. Note de présentation des premiers résultats du Recensement Général de la Population et de l'Habitat 2014 (Version Fr). 2015. Available online: https://www.hcp.ma/downloads/RGPH2014_t17441.html (accessed on 20 March 2020).

6. United Nations. Transforming Our World: The 2030 Agenda for Sustainable Development, Resolution A/Res/70/1. 2015. Available online: https:/www.un.org/ga/search/view_doc.asp?symbol=A/RES/70/1Lang=E (accessed on 1 March 2020).

7. Zhao, S.; Zhou, D.; Zhu, C.; Sun, Y.; Wu, W.; Liu, S. Spatial and Temporal Dimensions of Urban Expansion in China. Environ. Sci. Technol. 2015, 49, 9600-9609. [CrossRef] [PubMed]

8. Soffianian, A.; Nadoushan, M.A.; Yaghmaei, L.; Falahatkar, S. Mapping and Analyzing Urban Expansion Using Remotely Sensed Imagery in Isfahan, Iran. World Appl. Sci. J. 2010, 9, 1370-1378.

9. Xiong, Y.; Pan, R.; Xu, G.; Jiao, L.; Li, K. A comparison of spatial and temporal characteristics of urban expansion in India during 1990-2014. Prog. Geogr. 2019, 38, 271-282.

10. Bounoua, L.; Nigro, J.; Thome, K.; Zhan, P.; Lachir, A. Mapping Urbanization in the United States for 2020. In Proceedings of the IGARSS 2018, IEEE International Geoscience and Remote Sensing Symposium, Valencia, Spain, 22-27 July 2018; pp. 854-857.

11. Azmi, R.; Saadane, A.; Kacimi, I. Estimation of spatial distribution and temporal variability of land surface temperature over Casablanca and the surroundings of the city. Int. J. Innov. Appl. Stud. 2015, 11, 49-57.

12. Bahi, H.; Rhinane, H.; Bensalmia, A.; Fehrenbach, U.; Scherer, D. Effects of Urbanization and Seasonal Cycle on the Surface Urban Heat Island Patterns in the Coastal Growing Cities: A Case Study of Casablanca, Morocco. Remote Sens. 2016, 8, 829. [CrossRef]

13. Lachir, A.; Bounoua, L.; Zhang, P.; Thome, K.; Messouli, M. Modeling the Urban Impact on Semiarid Surface Climate: A Case Study in Marrakech, Morocco. Can. J. Remote Sens. 2016, 42, 379-395. [CrossRef] 
14. Fathi, N.; Bounoua, L.; Messouli, M. A Satellite Assessment of the Urban Heat Island in Morocco. Can. J. Remote Sens. 2019. [CrossRef]

15. UN-Habitat. Sustainable Development Goal 11+ Make Cities and Human Settlements Inclusive, Safe, Resilient and Sustainable: A Guide to Assist National and Local Governments to Monitor and Report on SDG Goal 11+ Indicators. 2018. Available online: https://smartnet.niua.org/sites/default/files/resources/sdg goal_11_monitoring_framework.pdf (accessed on 1 March 2020).

16. Bounoua, L.; Nigro, J.; McAndrew, B. Personal communication. In The SDG 11.3.1 Indicator; Goddard Space Flight Center: Greenbelt, MD, USA, 2019.

17. United Nations Statistics. Division Population Density and Urbanization. 1998. Available online: https: //unstats.un.org/unsd/demographic/sconcerns/densurb/densurbmethods.htm (accessed on 2 April 2020).

18. Diksha, S.; Kumar, A. Analysing urban sprawl and land consumption patterns in major capital cities in the Himalayan region using geoinformatics. Appl. Geogr. 2017, 89, 112-123. [CrossRef]

19. Li, X.; Zhao, L.; Li, D.; Xu, H. Mapping Urban Extent Using Luojia 1-01 Nighttime Light Imagery. Sensors 2018, 18, 3665. [CrossRef] [PubMed]

20. Norjamaki, I.; Tokola, T. Comparison of Atmospheric Correction Methods in Mapping Timber Volume with Multitemporal Landsat Images in Kainuu, Finland. Photogramm. Eng. Remote Sens. 2007, 73, 155-163. [CrossRef]

21. Lillesand, T.M.; Kiefer, R.W.; Chipman, J.W. Remote Sensing and Image Interpretation; John Wiley Sons, Inc.: Hoboken, NJ, USA, 2004.

22. Imhoff, M.L.; Zhang, P.; Wolfe, R.E.; Bounoua, L. Remote Sensing of the Urban Heat Island Effect across Biomes in the Continental USA. Remote Sens. Environ. 2010, 114, 504-513. [CrossRef]

23. Haut-Commissariat au Plan du Royaume du Maroc. Recensement Général de la Population et de l'Habitat. Centre de Lecture Automatique des Documents. Available online: https:/www.hcp.ma/Recensementgeneral-de-la-population-et-de-1-habitat-2004_a633.html (accessed on 2 April 2020).

24. Bounoua, L.; Nigro, J.; Zhang, P.; Lachir, A.; Thome, K. Mapping Urbanization in the United States from 2001-2011. Appl. Geogr. 2018, 90, 123-133. [CrossRef]

25. Démographie Marocaine. Tendances Passées et Perspectives d'Avenir. Available online: https://www.hcp. ma/downloads/Demographie_t11876.html (accessed on 3 April 2020).

26. Bounoua, L.; Nigro, J.; Thome, K.; Zhang, P.; Fathi, N.; Lachir, A. A Method for Mapping Future Urbanization in the United States. Urban Sci. 2018, 2, 40. [CrossRef]

27. Lahsini, C. Tourism in Marrakech Breaks All Records in 2017. Available online: https: //www.moroccoworldnews.com/2018/01/237558/tourism-marrakech-breaks-records-2017/ (accessed on 2 March 2020).

28. Habitat III. Third United Nations Conference on Housing and Sustainable Urban Development, National Report. Available online: http://habitat3.org/wp-content/uploads/Morocco-National-Report-Habitat-IIIFinal-1.pdf (accessed on 3 April 2020).

29. Report of the Secretary-General, Special Edition: Progress towards the Sustainable Development Goals. Progress of Goal 11 in 2019. Available online: https://sustainabledevelopment.un.org/sdg11 (accessed on 2 April 2020).

(C) 2020 by the authors. Licensee MDPI, Basel, Switzerland. This article is an open access article distributed under the terms and conditions of the Creative Commons Attribution (CC BY) license (http://creativecommons.org/licenses/by/4.0/). 